\title{
Editorial
}

\section{Countering more virulent SARS-CoV-2 variants will require a smarter pandemic response}

\author{
Kirsten Patrick MB BCh MSc
}

\begin{abstract}
n Cite as: CMAJ 2021 October 25;193:E1633-4. doi: 10.1503/cmaj.211656; early-released October 5, 2021
\end{abstract}
See related article at www.cmaj.ca/lookup/doi/10.1503/cmaj.211248

$\mathbf{N}$ ew research shows that SARS-CoV-2 variants of concern (VOCs) are more virulent than the native strain, in addition to being more transmissible. ${ }^{1}$ Fisman and Tuite used Ontario's COVID-19 case data to estimate the virulence of the Alpha/B1.1.17, Beta/B.1.351, Gamma/P.1 and Delta/B.1.617 variants compared with the initial wild-type strain of SARS-CoV-2. They found higher risks of hospitalization, admission to intensive care and death with VOCs, particularly the Delta variant.

Canada is battling a different pandemic from the one it faced in early 2020. The virus has become smarter and more dangerous, which means that we need to be smarter too. Canada's governments can keep people safe by enacting policies that wisely combine all the measures that have been shown to be effective.

The earlier-than-expected arrival of SARS-CoV-2 vaccines brought hope that society could reopen and return to normal more quickly than anticipated. After several rounds of lockdowns, physical distancing mandates and restrictions on businesses, people are understandably tired; the economic and mental strains of pandemic restrictions have been immense. Heading into summer, some governments elected to flip the switches on most public health measures to "OFF." Leaders in Alberta and Saskatchewan, for example, decided to disregard the cautions of scientists who warned of the dangers of VOCs; instead, they preached hope by promising the "best summer ever." Now, their health care systems face a demand for critical care that is higher than ever, exhausted health care workers are burdened by moral distress, and the knock-on effects of cancelled procedures will affect peoples' health for years to come.

The enhanced virulence of SARS-CoV-2 variants, ${ }^{1}$ their capacity to cause breakthrough infections in fully vaccinated people $^{3}$ and reports of reduced effectiveness of approved vaccines against the Delta variant are not the only factors dimming the light at the end of the pandemic tunnel. A perverse pandemic of misinformation has led to widespread vaccine hesitancy and refusal in Canada and beyond, ${ }^{4,5}$ jeopardizing efforts to reach SARS-CoV-2 herd immunity, which would facilitate the relaxation of public health measures. ${ }^{6}$

SARS-CoV-2 vaccines clearly work to prevent severe COVID-19 and death; most patients with COVID-19 currently requiring critical care and respiratory support are unvaccinated, according to North American data. ${ }^{7,8}$ Thus, every eligible person in Canada for whom the vaccine is not contraindicated should receive it so that children younger than 12 years who are not yet vaccine-eligible, and people with risk factors for severe COVID-19, can be protected. Governments should step up efforts to deliver vaccinations to those eligible and prioritize the approval of safe vaccines for children.

Vaccine mandates and vaccine passport initiatives have effectively persuaded many previously vaccine-hesitant people to seek immunization. Although mandates may have sparked demoralizing protests, requirements that people be vaccinated to work or enter certain settings are supportable; the Ontario Human Rights Commission recently stated that people who hold antivaccination or antimask beliefs have the right not to use these protections, but they do not have the right to threaten the health of others. ${ }^{4}$ Governments should extend vaccine mandates to require more public sector workers who operate in congregate settings, such as educators, to prioritize the safety of their charges.

Mass protests are morally unjustified and should not be allowed at sites where they may threaten the well-being of others or hamper the delivery of essential services. Governments can mandate protest buffer zones around schools and hospitals; Quebec's National Assembly recently voted to pass a bill prohibiting antivaccine protesters from demonstrating near schools, daycares, hospitals, COVID-19 testing facilities and vaccine sites. ${ }^{9}$ Canada's health care and other essential workers deserve to feel safe and respected as they keep society functioning and safe by continuing to show up for work.

Governments should also provide financial and technical assistance to schools to optimize environmental safety and ventilation in classrooms. This, along with deployment of rapid antigen testing for asymptomatic people ${ }^{10}$ and optimized contact tracing in outbreak situations, will help both to protect children who cannot yet be vaccinated and to reduce circulation of SARS-CoV-2 in communities.

Swiftly identifying outbreaks and ensuring that people infected with SARS-CoV-2 self-isolate remains an important part of our pandemic defence against increasingly virulent SARS-CoV-2. The 
fastest way to stop any SARS-CoV-2 variant from spreading is to have fewer people share air. ${ }^{11}$ This means all levels of government must nimbly and decisively respond to emerging outbreaks by temporarily reintroducing enhanced physical distancing measures, supported by clear messaging.

Lastly, it is imperative that Canada supports efforts to ramp up vaccine availability in countries with poor access by donating excess stock and supporting global agreements that will allow countries to manufacture vaccines locally. International travel has resumed and, with the ever-present threat of the emergence and spread of new VOCs, COVID-19 will cast a dismal shadow over all our lives for years to come if a coordinated global response does not materialize.

As Canada heads into its second winter of the COVID-19 pandemic, we must collectively learn from past mistakes and make sure to use all the tools at our disposal to avoid future lockdowns and prevent further devastation to our health care infrastructure.

\section{References}

1. Fisman DN, Tuite AR. Evaluation of the relative virulence of novel SARS-CoV-2 variants: a retrospective cohort study in Ontario, Canada. CMAJ 2021 October 5 [Epub ahead of print]. doi: 10.1503/cmaj.211248.

2. Austen I. Alberta's 'best summer ever' ends with an overwhelmed medical system. The New York Times 2021 Sept. 24. Available: https://www.nytimes. com/2021/09/24/world/canada/canada-alberta-covid-cases.html (accessed 2021 Sept. 25).

3. Bergwerk M, Gonen T, Lustig Y, et al. COVID-19 breakthrough infections in vaccinated health care workers. N Engl J Med 2021 July 28 [Epub ahead of print]. doi: 10.1056/NEJMoa2109072.

4. OHRC policy statement on COVID-19 vaccine mandates and proof of vaccine certificates. Toronto: Ontario Human Rights Commission; 2021. Available: www. ohrc.on.ca/en/news_centre/ohrc-policy-statement-covid-19-vaccine-mandates -and-proof-vaccine-certificates (accessed 2021 Sept. 25).
5. Anti-vaccine protesters clash with police In Melbourne, Australia, for the 2nd day. NPR (National Public Radio) 2021 Sept. 21. Available: https://www.npr .org/2021/09/21/1039301977/anti-vaccine-protesters-clash-with-police-in -melbourne-for-the-second-straight-d (accessed 2021 Sept. 25).

6. Bolotin S, Wilson S, Murti M. Achieving and sustaining herd immunity to SARSCoV-2. CMAJ 2021;193:E1089.

7. Confirmed cases of COVID-19 following vaccination in Ontario: December 14 2020 to September 4, 2021 [news release]. Toronto: Public Health Ontario; 2021 Sept. 4. Available: https://www.publichealthontario.ca/-/media/documents/ ncov/epi/covid-19-epi-confirmed-cases-post-vaccination.pdf?la=en (accessed 2021 Sept. 25).

8. Scobie HM, Johnson AG, Suthar AB, et al. Monitoring incidence of COVID-19 cases, hospitalizations, and deaths, by vaccination status: 13 U.S. jurisdictions, April 4-July 17, 2021. MMWR Morb Mortal Wkly Rep 2021;70:1284-90.

9. Ross S, Lofaro J. Quebec swiftly passes new bill to prohibit anti-vaccine protests near schools, hospitals. CTV News Montreal 2021 Sept. 23, updated 2021 Sept. 24. Available: https://montreal.ctvnews.ca/quebec-swiftly-passes-new-bill-to -prohibit-anti-vaccine-protests-near-schools-hospitals-1.5597380 (accessed 2021 Sept. 25).

10. Schwartz KL, McGeer AJ, Bogoch II. Rapid antigen screening of asymptomatic people as a public health tool to combat COVID-19. CMAJ 2021;193:E449-52.

11. Addleman $\mathrm{S}$, Leung $\mathrm{V}$, Asadi $\mathrm{L}$, et al. Mitigating airborne transmission of SARS CoV-2. CMAJ 2021;193:E1010-1.

Competing interests: See www.cmaj.ca/site/misc/cmaj_staff.xhtml.

Affiliation: Interim editor-in-chief, CMAJ

Content licence: This is an Open Access article distributed in accordance with the terms of the Creative Commons Attribution (CC BY-NCND 4.0) licence, which permits use, distribution and reproduction in any medium, provided that the original publication is properly cited, the use is noncommercial (i.e., research or educational use), and no modifications or adaptations are made. See: https://creativecommons.org/ licenses/by-nc-nd/4.0/

Correspondence to: CMAJ editor, editorial@cmaj.ca 